\title{
Analysis of Y-chromosome Variability and its Comparison with mtDNA Variability Reveals Different Demographic Histories Between Islands in the Azores Archipelago (Portugal)
}

\author{
R. Montiel, ${ }^{1 *}$ C. Bettencourt, ${ }^{1}$ C. Silva, ${ }^{1}$ C. Santos, ${ }^{2,3}$ M. J. Prata ${ }^{4}$ and M. Lima ${ }^{1}$ \\ ${ }^{1}$ Center of Research in Natural Resources (CIRN), University of the Azores, Ponta Delgada, Portugal \\ ${ }^{2}$ Unity of Anthropology, Department BABVE, Autonomous University of Barcelona, Barcelona, Spain \\ ${ }^{3}$ Department of Anthropology, University of Coimbra, Coimbra, Portugal \\ ${ }^{4}$ Institute of Pathology and Molecular Immunology of the University of Porto (IPATIMUP), Porto, Portugal
}

\section{Summary}

We determined the Y-chromosomal composition of the population of the Azores Islands (Portugal), by analyzing 20 binary polymorphisms located in the non-recombining portion of the Y-chromosome (NRY), in 185 unrelated individuals from the three groups of islands forming the Archipelago (Eastern, Central and Western). Similar to that described for other Portuguese samples, the most frequent haplogroups were R1(xR1b3f) (55.1\%), E(xE3a) (13\%) and J (8.6\%). Principal components analysis revealed a Western European profile for the Azorean population. No significant differences between Azores and mainland Portugal were observed. However, the haplogroup distribution across the three groups of islands was not similar $(P<0.003)$. The Western group presented differences in the frequencies of haplogroups R1, E(xE3a) and I1b2 $(27.3 \%, 22.7 \%$ and $13.6 \%$, respectively) when compared to the other two groups. An assessment of the NRY variability, and its comparison with mitochondrial DNA (mtDNA) variability, was further evidence of the differential composition of males during the settlement of the three groups of islands, contrary to what has been previously deduced for the female settlers using mtDNA data.

Keywords: Y chromosome, haplogroups, binary markers, SNP, Azores Islands, demographic history

\section{Introduction}

The Azores Islands (Portugal) are located in the Atlantic Ocean, $1500 \mathrm{~km}$ from the European Mainland. Nine islands, clustered in 3 geographical groups (Eastern, Central and Western) form this Archipelago (Figure 1). The Azores have an area of $2344 \mathrm{Km}^{2}$ and a total population of 237315 inhabitants, distributed in a very asymmetric way (134 885 inhabitants in the Eastern group, 98101 in the Central, and only 4329 inhabitants in the Western group) (INE, 2001). The Islands were discovered, unin-

\footnotetext{
* Corresponding author: Rafael Montiel, Ph.D., CIRN, Department of Biology, University of the Azores, 9501-801 Ponta Delgada, Azores, Portugal. Phone: ++ (351) 296650111; Fax: ++ (351) 296650100, E-mail: montiel@notes.uac.pt.
}

habited, by Portuguese navigators in the early 15 th century. Starting with the islands of the Eastern group, the process of settlement was initiated by 1439, with main imports coming from Mainland Portugal and Madeira Island (Matos, 1989a). Immigrants from other European regions (Flanders, Spain, Italy, France, England, Germany and Scotland) made up part of the first groups of settlers but, with the exception of the Flemish, their overall contribution is thought to be less than that of the Portuguese groups. An African influence, derived mainly from the contribution of African and Moorish slaves, is also reported (Matos, 1989b). Furthermore, there is evidence that Sephardic Jews, expelled from the Iberian Peninsula, also contributed to the peopling of this Archipelago (Mendonça, 1996). Historical 


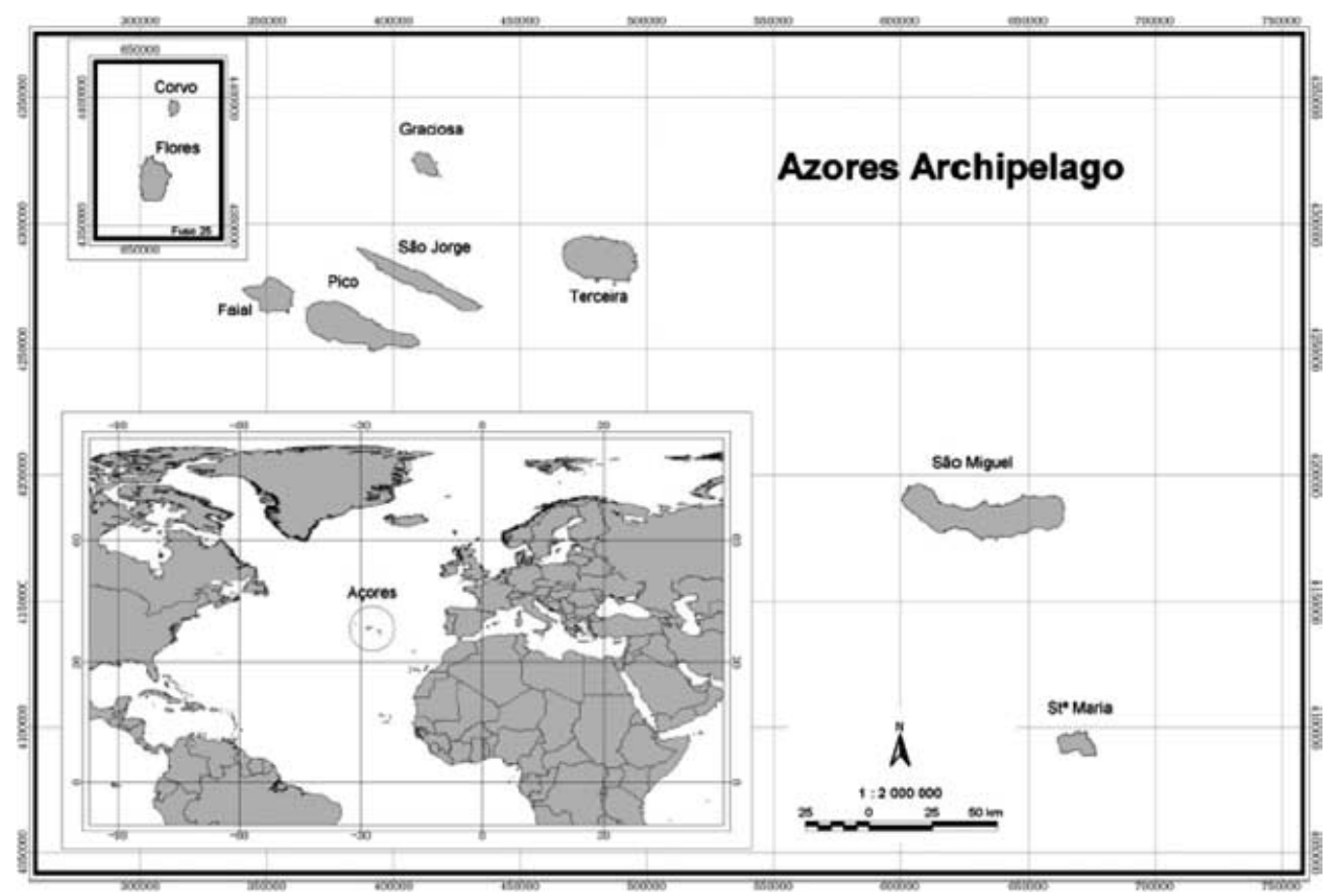

Figure 1 Geographical location of the Azores. The Archipelago is formed by three groups of islands, Western (Flores and Corvo), Central (Faial, Pico, São Jorge, Graciosa and Terceira) and Eastern (São Miguel and Santa Maria). Source: Geography section, Department of Biology, University of the Azores.

documents, however, are not sufficient to provide accurate information concerning the demographics of settlement, and do not report how these distinct contributions were distributed among the 3 groups of islands. Genetic characterization of the Azorean population should allow the reconstruction of a more comprehensive picture of these processes. Studies using autosomal short tandem repeats (STR) markers have shown that the Azores fit well into the pattern of variation described for other European populations. However, signs of genetic affinities with non-Europeans, namely North Africans, have been described (Silva et al. in press). Phylogeographic analysis of mitochondrial DNA (mtDNA) from the Azorean population showed a major contribution from mainland Portugal, as well as evidence of influxes from Northern Europeans, Africans, and Jewish groups (Santos et al. 2003). To further assess the genetic diversity of the Azorean populations, with the aim of understanding the demographic history of the Azores, studies of markers from the non-recombining region of the Y-chromosome (NRY) have been undertaken (this study; Pacheco et al. 2004). Here we report on the frequency of Y-chromosome haplogroups found in Azorean populations. An assessment of the relative diversity and phylogeographic context of the Azorean Y-chromosome pool has also been performed.

\section{Materials and Methods}

One hundred and eighty five unrelated individuals born in the Azores and of Azorean ancestry were sampled by buccal swabs. Sample location was defined using the island of origin of the earliest known paternal ancestor (corresponding at least to the paternal grandfather's birthplace). Twenty-two individuals were from the Western island group, 76 from the Central group and 87 from the Eastern group. Voluntary donors were asked for informed consent and to fill in a genealogical questionnaire concerning the birthplaces of all their known ancestors.

The polymorphic sites in our study included a set of 20 previously published binary NRY markers (Table 1 and Figure 2). For some of these markers we designed new primers to amplify shorter fragments. Markers M2, M9, M20, M26, M40 (SRY 4064), M52, M60, M74, M94, M167 (SRY-2627), M173, M174, M175, 


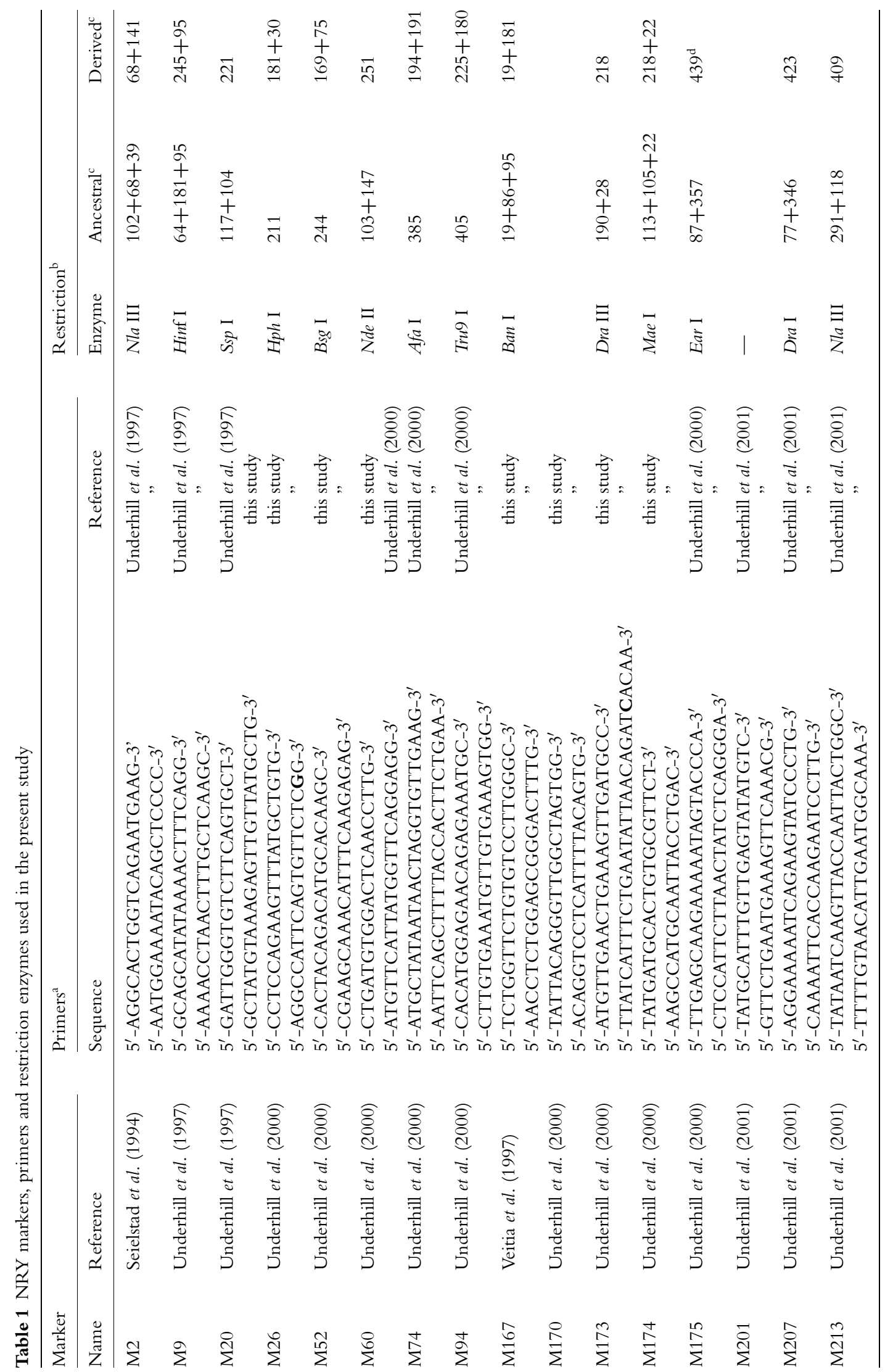




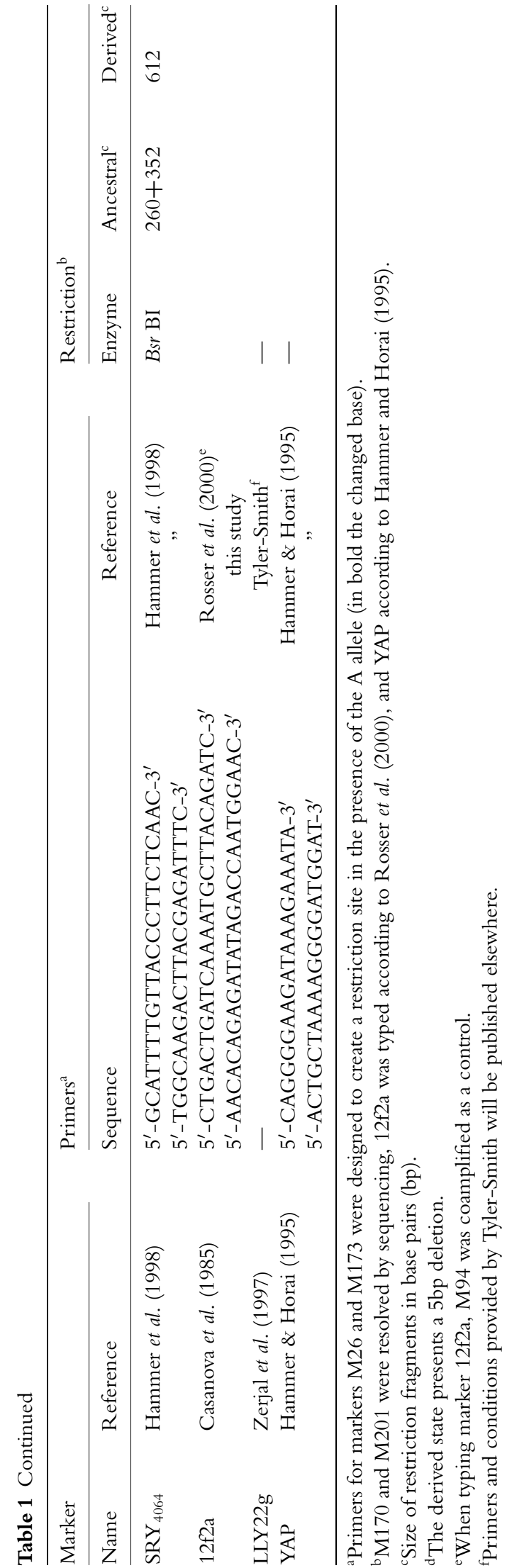

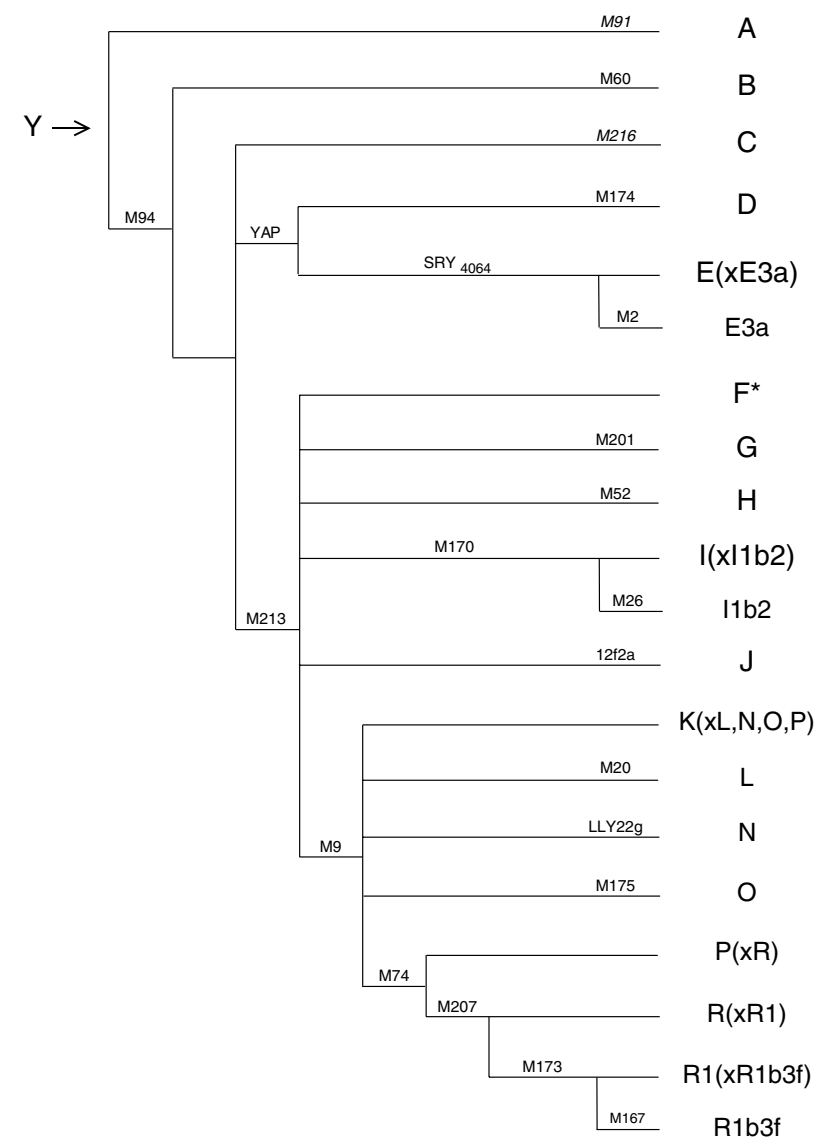

Figure 2 Phylogenetic tree of binary Y-chromosomal haplogroups as defined by the markers typed in this study. Italicized markers were not typed, but their allelic states in the chromosomes analyzed can be deduced from the YCC2003 phylogenetic tree (Jobling \& Tyler-Smith, 2003).

M207 and M213 were typed by PCR followed by digestion with restriction enzymes. Markers M170 and M201 were resolved by sequencing. Marker $12 f 2$ (Casanova et al. 1985) was typed according to Rosser et al. (2000), using a new designed reverse primer. Primers and conditions for PCR typing the LLY22g marker (Zerjal et al. 1997) were kindly provided by C. Tyler-Smith and will be published elsewhere. The Y Alu-insertion polymorphism (YAP) at DYS287 was typed as described by Hammer \& Horai (1995). We followed a hierarchical typing, starting with the M9 marker. Samples with the ancestral state for this marker were then typed for M213. Subsequent ancestral state samples were typed for YAP and M94, successively. Additional genotyping of samples carrying the derived alleles for each of these markers was restricted to markers on the 
Table 2 NRY haplogroup distribution in the total sample of the Azores and in the three groups of islands

\begin{tabular}{|c|c|c|c|c|c|}
\hline \multirow[b]{2}{*}{ Haplogroup } & \multirow[b]{2}{*}{ Marker $^{\mathrm{a}, \mathrm{b}}$} & \multicolumn{4}{|l|}{ N (\%) } \\
\hline & & Azores & Western & Central & Eastern \\
\hline A & M91(M94-) & 0 & 0 & 0 & 0 \\
\hline $\mathrm{B}$ & M60 & 0 & 0 & 0 & 0 \\
\hline $\mathrm{C}$ & M216,M94(M60-,YAP-,M213-) & 0 & 0 & 0 & 0 \\
\hline $\mathrm{D}$ & M174 & 0 & 0 & 0 & 0 \\
\hline $\mathrm{E}(\mathrm{xE} 3 \mathrm{a})$ & $\mathrm{SRY}_{4064}(\mathrm{M} 2-)$ & $24(13)$ & $5(22.7)$ & $7(9.2)$ & $12(13.8)$ \\
\hline E3a & M2 & 0 & 0 & 0 & 0 \\
\hline $\mathrm{F}(\mathrm{xH}, \mathrm{J}, \mathrm{K})^{\mathrm{c}}$ & M213(M52-,12f2a-,M9-) & $5(2.7)$ & $1(4.5)$ & $4(5.3)$ & 0 \\
\hline G & M201 & $6(3.2)$ & $2(9.1)$ & $1(1.3)$ & $3(3.4)$ \\
\hline $\mathrm{H}$ & M52 & 0 & 0 & 0 & 0 \\
\hline $\mathrm{I}^{\mathrm{c}}$ & M170 & $2(1.1)$ & 0 & $2(2.6)$ & 0 \\
\hline $\mathrm{I}(\mathrm{xI} 1 \mathrm{~b} 2)$ & M170(M26-) & $6(3.2)$ & $1(4.5)$ & $4(5.3)$ & $1(1.1)$ \\
\hline I1b2 & M26 & $8(4.3)$ & $3(13.6)$ & $2(2.6)$ & $3(3.4)$ \\
\hline $\mathrm{J}$ & $12 \mathrm{f} 2 \mathrm{a}$ & $16(8.6)$ & $2(9.1)$ & $11(14.5)$ & $3(3.4)$ \\
\hline $\mathrm{K}(\mathrm{xL}, \mathrm{N}, \mathrm{O}, \mathrm{P})$ & M9(M20-,LLY22g-,M175-,M74-) & $5(2.7)$ & 0 & $2(2.6)$ & $3(3.4)$ \\
\hline $\mathrm{L}$ & M20 & $2(1.1)$ & 0 & 0 & $2(2.3)$ \\
\hline $\mathrm{N}$ & LLY22g & 0 & 0 & 0 & 0 \\
\hline $\mathrm{O}$ & M175 & 0 & 0 & 0 & 0 \\
\hline $\mathrm{P}(\mathrm{xR})$ & M74(M207-) & $1(0.5)$ & $1(4.5)$ & 0 & 0 \\
\hline $\mathrm{R}^{\mathrm{c}}$ & M207 & $3(1.6)$ & 0 & $3(3.9)$ & 0 \\
\hline $\mathrm{R} 1^{\mathrm{c}}$ & M173 & $1(0.5)$ & 0 & $1(1.3)$ & 0 \\
\hline R1(xR1b3f) & M173(M167-) & $102(55.1)$ & $6(27.3)$ & $37(48.7)$ & $59(67.8)$ \\
\hline \multirow[t]{2}{*}{ R1b3f } & M167 & $4(2.2)$ & $1(4.5)$ & $2(2.6)$ & $1(1.1)$ \\
\hline & Total & 185 & 22 & 76 & 87 \\
\hline
\end{tabular}

${ }^{a}$ Most distal mutated marker according to the YCC2003 tree (Jobling \& Tyler-Smith, 2003) (and relevant markers with confirmed ancestral state, denoted by a minus '-' symbol).

${ }^{\mathrm{b}}$ Italicized markers were not typed, but their allelic states in the chromosomes analyzed can be deduced from the YCC phylogenetic tree.

'Samples belonging to these haplogroups were not tested for additional markers because DNA was finished.

appropriate branch of the YCC haplogroup tree (Jobling \& Tyler-Smith, 2003). The YCC updated phylogeny (YCC2003; Jobling \& Tyler-Smith, 2003) was followed to name the haplogroups. Differences in proportions of haplogroups were assessed by the Fisher exact test. An exact test of population differentiation (Raymond \& Rousset, 1995) was used to compare the haplogroup distribution between populations. ANOVA and t-tests were used to compare Nei's genetic diversities.

\section{Results and Discussion}

Table 2 shows the distribution of $\mathrm{Y}$ chromosome haplogroups in the Azores Islands. Chromosomes belonging to haplogroup R1(xR1b3f) were the most frequent (55.1\%). Haplogroup R1, by far the most frequent in European populations (Semino et al. 2000), embraces several subgroups showing different phylogeographies. Hurles et al. (1999) proposed that subgroup R1b3f, defined by the marker M167 (SRY-2627), arose in Iberia, and nowadays reaches high frequencies only in Basques and Catalans. In the Azores, R1b3f chromosomes were found at a low frequency (with a minimum of $2.2 \%$ ), in agreement with previous results for other Portuguese and Spanish samples (Rosser et al. 2000). Haplogroup $\mathrm{E}(\mathrm{xE} 3 \mathrm{a})$ was the second most frequent in the Azores, and was represented by $13 \%$ of the chromosomes analyzed. This proportion is statistically similar to those reported for North (10.7\%; Rosser et al. 2000 and 11.9\%; Carvalho-Silva et al. 2001) and South Portugal (17.5\%; Rosser et al. 2000 and 24.5\%; Pereira et al. 2000a). The high frequency of this marker in South Portugal has been considered as evidence of a genetic influx from North Africa (Pereira et al. 2000a). Further analysis of E(xE3a) 
chromosomes in the Azores, Mainland Portugal, and North and Sub-Saharan Africa would be relevant, to assess to what extent these chromosomes were introduced into the Azores by Portuguese settlers or were directly brought by Moorish and/or sub-Saharan slaves. Haplogroup I1b2 (M26), which reaches at least 4.3\% in the Azorean population, has been found in Sardinia at a high frequency (34.6\% to $48.7 \%$ ) (Semino et al. 2000; Francalacci et al. 2003; Zei et al. 2003) and also in Basques (4.4\% to 9\%) (Semino et al. 2000; Bosch et al. 2001). This haplogroup is rarely found in other Western European populations (Semino et al. 2000). Unfortunately, the marker defining this group has not been tested in Mainland Portugal, and therefore it is difficult to discuss whether the I1b2 chromosomes found in the Azores came with Portuguese settlers or, alternatively, represent signs of a direct Italian (Sardinian) or Basque influx. The frequency of Haplogroup J (12f2a) found in our sample $(8.6 \%)$ is statistically similar to that found in North (6.4\%; Rosser et al. 2000 and 6.5\%; CarvalhoSilva et al. 2001) and South Portugal (8.7\%; Rosser et al. 2000). This haplogroup is frequent in the Middle East (Rosser et al. 2000; Semino et al. 2000) and in several Jewish groups (Hammer et al. 2000; Nebel et al. 2001), reaching its highest frequency among Cohanim Jews (both Ashkenazim and Sephardim) (Behar et al. 2003). Other haplogroups represented in the Azores Islands are G (3.2\%) and L (1.1\%). Haplogroup G (M201) is increasingly distributed from Western to Eastern Europe (Semino et al. 2000), and haplogroup L (M20) has been found in India (Jobling \& Tyler-Smith, 2003). As both $G$ and $L$ have not been resolved for other Portuguese samples, their presence in the Azores need to be further investigated.

When comparing the global Y chromosome haplogroup distribution of the Azores with that of samples from Mainland Portugal (Rosser et al. 2000) no significant differences were found (exact test of population differentiation; $P=0.895$ for South and $P=0.753$ for North Portugal). Furthermore, Principal Components (PC) analysis showed that the Azorean population is a typical Western European population (Figure 3).

When comparing the three groups of islands, important differences were detected, particularly concerning the Western group, which proved to be the most differentiated in the PC analysis (Figure 3). In fact, hap- logroup frequencies across the three groups of islands are statistically different (exact test of population differentiation; $P<0.003)$, likely due to differences in the frequency of: (i) haplogroups $\mathrm{E}(\mathrm{xE} 3 \mathrm{a}), \mathrm{G}$, and I1b2, that are more frequent in the Western group; (ii) haplogroup $\mathrm{J}$, that is more frequent in the Central group, and (iii) haplogroup R1 that shows a noticeable decrease in frequency from the Eastern to the Western group (Table 2). The Western group was the most differentiated, showing differences from both the Central (exact test of population differentiation; $P=0.025$ ) and Eastern (exact test of population differentiation; $P=0.008$ ) groups. Differences between Central and Eastern groups were not significant (exact test of population differentiation; $P=0.063)$. Of particular interest are the differences in $\mathrm{E}(\mathrm{xE} 3 \mathrm{a})$ proportions since, as mentioned before, this haplogroup may contain sub-Saharan haplotypes. The presence of African slaves has been well documented for several Azorean islands, namely for the two islands that constitute the Western group (Flores and Corvo) (Gomes, 1997; Lima, unpublished data), in which we found the frequency of $\mathrm{E}(\mathrm{xE} 3 \mathrm{a})$ chromosomes $(22.7 \%)$ to be higher when compared to the Central $(9.2 \%)$ or the Eastern (13.7\%) groups. This result becomes more relevant if we consider that mtDNA data did not show evidence of sub-Saharan African influences in the Western group (Santos et al. 2003), as might be expected. Biodemographic analysis showed that the number of male and female slaves that came to these groups of islands was similar (Lima, unpublished data). Genetic drift, invoked as the force responsible for the atypical mtDNA haplogroup distribution observed in the Western group (Santos et al. 2003), could also be responsible for the loss of sub-Saharan mitochondrial lineages, disregarding differences in the female composition at the time of settlement. In fact, the Western group has the lowest number of inhabitants and therefore should be the most sensitive to drift. Meanwhile, the high frequency of $\mathrm{E}(\mathrm{xE} 3 \mathrm{a})$ chromosomes, and the low frequency of chromosomes belonging to the European R1 haplogroup, seem to indicate that the male composition at settlement may have been different for the Western group of islands.

To further investigate the differences found amongst groups of islands we compared the Y-chromosome diversity relative to the respective mtDNA diversity. This comparison is useful to detect differences in the fitness or 
Chromosomes grouped according to Rosser et al. (2000)

\begin{tabular}{|c|c|c|c|c|c|}
\hline $\mathrm{Hg}$ & YCC2003 & $\begin{array}{c}\text { Azores } \\
\mathrm{N}=185\end{array}$ & $\begin{array}{l}\text { Western } \\
\qquad \mathrm{N}=22\end{array}$ & $\begin{array}{c}\text { Central } \\
\qquad N=76\end{array}$ & $\begin{array}{l}\text { Eastern } \\
\qquad \mathrm{N}=87\end{array}$ \\
\hline $\mathrm{HG} 1,3$ & $P(x R 1 b 3 f)$ & 57.84 & 31.82 & 53.95 & 67.82 \\
\hline HG2 & $Y(x A, D, E, J, K)$ & 14.59 & 31.82 & 17.11 & 8.05 \\
\hline HG4 & D & 0 & 0 & 0 & 0 \\
\hline HG7 & A & 0 & 0 & 0 & 0 \\
\hline HG8 & E3a & 0 & 0 & 0 & 0 \\
\hline HG9 & $\mathrm{J}$ & 8.65 & 9.09 & 14.47 & 3.45 \\
\hline $\mathrm{HG} 12,16$ & $N$ & 0 & 0 & 0 & 0 \\
\hline HG21 & $E(x E 3 a)$ & 12.97 & 22.73 & 9.21 & 13.79 \\
\hline HG22 & R1b3f & 2.16 & 4.55 & 2.63 & 1.15 \\
\hline HG26 & $K(x N, P)$ & 3.78 & 0 & 2.63 & 5.75 \\
\hline
\end{tabular}

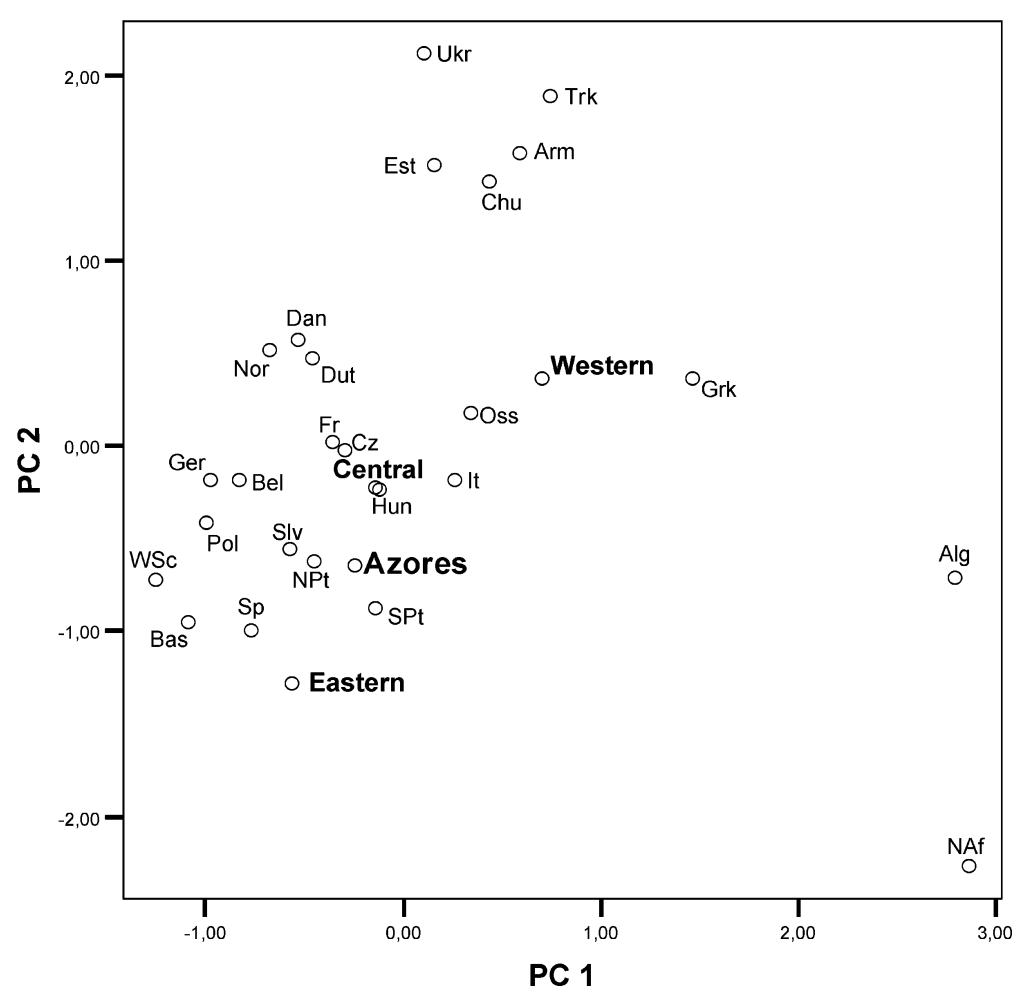

Figure 3 PC analysis of data from Rosser et al. (2000), the total sample from the Azores and from the Western, Central, and Eastern groups (values in \%). The first PC accounts for $62.63 \%$ of the variance, whereas the second accounts for $18.32 \%$. Alg, Algerian ( $\mathrm{N}=27)$; Arm, Armenian ( $\mathrm{N}=89$ ); NAf, Northern African ( $\mathrm{N}$ $=129)$; Bas, Basques $(\mathrm{N}=26)$; Bel, Belgian $(\mathrm{N}=92)$; Chu, Chuvash $(\mathrm{N}=17)$; $\mathrm{Cz}$, Czech ( $\mathrm{N}=53)$; Dan, Danish $(\mathrm{N}=56)$; Dut, Dutch $(\mathrm{N}=84)$; Est, Estonian $(\mathrm{N}=207)$; Fr, French $(\mathrm{N}=40)$; Ger, German $(\mathrm{N}=30)$; Grk, Greek $(\mathrm{N}=36)$; Hun, Hungarian $(\mathrm{N}=36)$; It, Italian $(\mathrm{N}=99)$; Nor, Norwegian $(\mathrm{N}=52)$; Oss, Ossetian ( $\mathrm{N}=47)$; Pol, Polish $(\mathrm{N}=112)$; NPort, Northern Portuguese $(\mathrm{N}$ $=328)$; SPort, Southern Portuguese $(\mathrm{N}=57)$; Slv, Slovakian $(\mathrm{N}=70)$; Trk, Turkish $(\mathrm{N}=167)$; Ukr, Ukrainian $(\mathrm{N}=27)$; WSc, Western Scottish $(\mathrm{N}=120)$; Sp, Spanish ( $\mathrm{N}=126)$ from Rosser et al. (2000). 
Table 3 Nei's gene diversity $(\hat{H})$ and its standard error (s.e.) (Nei, 1987), estimated for NRY and mtDNA data for the total sample of the Azores and for the three groups of islands

\begin{tabular}{lllllllll}
\hline & \multicolumn{3}{l}{$\mathrm{NRY}^{\mathrm{a}}$} & & & \multicolumn{3}{l}{$\mathrm{mtDNA}^{\mathrm{b}}$} \\
\cline { 2 - 4 } \cline { 7 - 8 } Population & $\mathrm{N}$ & $\hat{H}$ & s.e. & & $\mathrm{N}$ & $\hat{H}$ & s.e. \\
\hline Azores & 174 & 0.6265 & 0.0381 & & 146 & 0.8490 & 0.0201 \\
Western & 21 & 0.8571 & 0.0466 & & 36 & 0.8127 & 0.0393 \\
Central & 66 & 0.6499 & 0.0571 & & 60 & 0.8011 & 0.0418 \\
Eastern & 87 & 0.5215 & 0.0608 & & 50 & 0.8637 & 0.0307 \\
\hline
\end{tabular}

${ }^{a}$ Partially typed samples were removed.

${ }^{b}$ Reanalysis of data from Santos et al. (2003). Samples were regrouped into the following haplogroups: H,I,J,L,M,N,T,U23,U5,U6, K, V,W,X, R* and Other.

migration rate of males and females (Seielstad et al. 1998; Oota et al. 2001). Table 3 shows the Nei's diversity values of NRY and mtDNA obtained for the three groups of islands. An increase in NRY diversity from East to West is observed, resulting in the highest value for the Western group. Statistical analysis showed that the NRY genetic diversity between the groups of islands is significantly different (ANOVA, $\mathrm{F}=4.156 ; P=0.0173$ ). Furthermore, the diversity observed in the Western group is significantly different to that observed in the Central (t-test; $\mathrm{t}=2.811 ; P=0.0063)$ or in the Eastern ( $\mathrm{t}$ test; $\mathrm{t}=4.381 ; P<0.0001)$ groups. Meanwhile, the diversity values between the Central and Eastern groups are not statistically different (t-test; $t=1.498 ; P=$ $0.1363)$. Reanalysis of mtDNA data reported previously (Santos et al. 2003) showed that the mitochondrial DNA diversity is not statistically different (ANOVA; $\mathrm{F}=0.7847 ; P=0.4582$ ) among the three groups of islands. Differences in Y-chromosome variability, observed within the Archipelago, could be explained by a differential male composition during settlement, contrary to the similar female compositions that have been deduced from mtDNA data. As the number of male and female African slaves arriving into the Western group has been determined as similar to other island groups (Lima, unpublished data), as previously mentioned the differential Y-chromosomal composition probably results from the low number of European male settlers, as evidenced by the low frequency of haplogroup R1.

In conclusion, the Y-chromosome distribution in the Azores is similar to the distribution observed in other Western European populations, with no differences be- ing detected relative to samples from mainland Portugal. Better resolution should be obtained by assessing variation within haplogroups, by means of microsatellite analyses (Pacheco et al. in this issue), although a detailed study of Mainland Portugal is still required, especially for haplogroups R1, E(xE3a), J and I1b2. This analysis of the $\mathrm{Y}$ chromosome composition of the Azorean population allowed the detection of particular characteristics that could be related to specific migration events that have occurred since the time of settlement. Furthermore, we have found differences in the NRY variability among the three groups of islands forming the Archipelago. The comparison of the Y-chromosome and mitochondrial Nei's genetic diversity between the groups of islands provided clues about the processes responsible for this differentiation, suggesting a differential male composition at the time of settlement of the three groups of islands. This observation precludes considering the Azores as an unstructured population, and indicates that a representative sampling of each island is required to adequately describe its variability, both for population genetic studies and for forensic purposes.

Overall, the results obtained clearly exemplify the utility of comparing patrilineal and matrilineal variability and support the idea that the Azorean populations may emerge as a model to study the effects that isolation, genetic drift and differential settlement composition may have had in shaping the variability found in present day populations.

\section{Acknowledgments}

This work was supported by CIRN (POCTI/ARRA Açores/172). R.M. is a postdoctoral fellow of the Fundação para a Ciência e a Tecnologia (FCT) (SFRH/BPD/13256/2003). C.S. is the recipient of a Ph.D. grant from FCT (SFRH/BD/723/2000). The authors are indebted to all the participants in the study.

\section{References}

Behar, D. M., Thomas, M. G., Skorecki, K., Hammer, M. F., Bulygina, E., Rosengarten, D., Jones, A. L., Held, K., Moses, V., Goldstein, D., Bradman, N. \& Weale, M. E. (2003) Multiple origins of Ashkenazi Levites: Y chromosome evidence for both near eastern and European ancestries. Am J Hum Genet 73, 768-779. 
Bosch, E., Calafell, F., Comas, D., Oefner, P. J., Underhill, P. A. \& Bertranpetit, J. (2001) High-resolution analysis of Human Y-Chromosome variation shows a sharp discontinuity and limited gene flow between Northwestern Africa and the Iberian Peninsula. Am J Hum Genet 68, 1019-1029.

Carvalho-Silva, D. R., Santos, F. R., Rocha, J. \& Pena, S. D. J. (2001) The phylogeography of Brazilian Y-chromosome lineages. Am J Hum Genet 68, 281-286.

Casanova, M., Leroy, P., Boucekkine, C., Weissenbach, J., Bishop, C., Fellous, M., Purrello, M., Fiori, G. \& Siniscalco, M. (1985) A human Y-linked DNA polymorphism and its potential for estimating genetic and evolutionary distance. Science 230, 1403-1406.

Francalacci, P., Morelli, L., Underhill, P. A., Lillie, A. S., Passarino, G., Useli, A., Madeddu, R., Paoli, G., Tofanelli, S., Calò, C. M., Ghiani, M. E., Varesi, L., Memmi, M., Vona, G., Lin, A. A., Oefner, P. \& Cavalli-Sforza, L. L. (2003) Peopling of three Mediterranean islands (Corsica, Sardinia, and Sicily) inferred by Y-chromosome biallelic variability. Am J Phys Anthropo 121, 270-279.

Gomes, F. (1997) Flores Island: from rediscovery to actuality. Azores, Portugal: Câmara Municipal de Lajes das Flores (in Portuguese).

Hammer, M. F. \& Horai, S. (1995) Y-chromosomal DNA variation and the peopling of Japan. Am J Hum Genet 56, 951-962.

Hammer, M. F., Karafet, T., Rasanayagam, A., Wood, E. T., Altheide, T. K., Jenkins, T., Griffiths, R. C., Templeton, A. R. \& Zegura, S. L. (1998) Out of Africa and back again: nested cladistic analysis of human $\mathrm{Y}$ chromosome variation. Mol Biol Evol 15, 427-441.

Hammer, M. F., Redd, A. J., Wood, E. T., Bonner, M. R., Jarjanazi, H., Karafet, T., Santachiara-Benerecetti, S., Oppenheim, A., Jobling, M. A., Jenkins, T., Ostrer, H. \& BonneTamir, B. (2000) Jewish and Middle Eastern non-Jewish populations share a common pool of Y-chromosome biallelic haplotypes. Proc Natl Acad Sci USA 97, 6769-6774.

Hammer, M. F., Karafet, T. M., Redd, A. J., Jarjanazi, H., Santachiara-Benerecetti, S., Soodyall, H. \& Zegura, S. L. (2001) Hierarchical Patterns of Global Human Y-Chromosome Diversity. Mol Biol Evol 18, 11891203.

Hurles, M. E., Veitia, R., Arroyo, E., Armenteros, M., Bertranpetit, J., Pérez-Lezaun, A., Bosch, E., Shlumukova, M., Cambon-Thomsen, A., McElreavey, K., López de Munain, A., Rohl, A., Wilson, I. J., Singh, L., Pandya, A., Santos, F. R., Tyler-Smith, C. \& Jobling, M. A. (1999) Recent male-mediated gene flow over a linguistic barrier in Iberia, suggested by analysis of a Y-chromosomal DNA polymorphism. Am J Hum Genet 65, 1437-1448.

INE (2001) Estimation of resident population 2001 based on provisory results of Census 2001. Portugal: National Institute of Statistics (in Portuguese).
Jobling, M. A. \& Tyler-Smith, C. (2003) The human Y chromosome: an evolutionary marker comes of age. Nat Rev Genet 4, 598-612.

Karafet, T. M., Osipova, L. P., Gubina, M. A., Posukh, O. L., Zegura, S. L. \& Hammer, M. F. (2002) High levels of Y-chromosome differentiation among native Siberian populations and the genetic signature of a boreal huntergatherer way of life. Hum Biol 74, 761-789.

Matos, A. T. (1989a) Settlement and Colonization of the Azores. Portugal no Mundo 12, 185-188 (in Portuguese).

Matos, A. T. (1989b) Origin and Reminiscences of the Atlantic Islands Settlers. In: Actas do Congresso Internacional Bartolomeu Dias e a sua Época III, pp. 241-252. Portugal: Porto University (in Portuguese).

Mendonça, L. (1996) Azores History - General Vision (centuries $X V$ to XIX). Ponta Delgada, Azores, Portugal: Centre of Tecnological Suport to Education (in Portuguese).

Nebel, A., Filon, D., Brinkmann, B., Majumder, P. P., Faerman, M. \& Oppenheim, A. (2001) The Y chromosome pool of Jews as part of the genetic landscape of the Middle East. Am J Hum Genet 69, 1095-1112.

Nei, M. (1987) Molecular evolutionaty genetics. New York: Columbia University Press.

Oota, H., Settheetham-Ishida, W., Tiwawech, D., Ishida, T. \& Stoneking, M. (2001) Human mtDNA and YChromosome variation is correlated with matrilocal versus patrilocal residence. Nat Genet 29, 20-21.

Pacheco, P. R., Branco, C. C., Cabral, R., Costa, S., Aráujo, A. L., Peixto, B. R., Mendonca, P. \& Mota-Vieira, L. (2004) The Y-Chromosomal Heritage of the Azores Islands Population. Ann Hum Genet doi:10.1046/j.15298817.2004.00147.x.

Pereira, L., Brion, M. J., Prata, M. J., Jobling, M. A., Carracedo, A. \& Amorim, A. (2000a) Gradient of Y chromosome haplogroup 21 across the Western Iberia. In: Progress in Forensic Genetics 8 (eds. G. F. Sensabaugh, P. J. Lincoln \& B. Olaisen), pp 281-283. Elsevier Science B. V.

Pereira, L., Prata, M. J., Jobling, M. A. \& Amorim, A. (2000b) Analysis of the Y-chromosome and mitochondrial DNA pools in Portugal. In: Archaeogenetics: DNA and the population prehistory of Europe (eds. C. Renfrew \& K. Boyle), pp 191-195. Cambridge: McDonald Institute for Archaeological Research.

Raymond, M. \& Rousset, F. (1995) An exact test for population differentiation. Evolution 49, 1280-1283.

Rosser, Z. H., Zerjal, T., Hurles, M. E., Adojaan, M., Alavantic, D., Amorim, A., Amos, W., Armenteros, M., Arroyo, E., Barbujani, G., Beckman, G., Beckman, L., Bertranpetit, J., Bosch, E., Bradley, D. G., Brede, G., Cooper, G., Côrte-Real, H. B. S. M., de Knijff, P., Decorte, R., Dubrova, Y. E., Evgrafov, O., Gilissen, A., Glisic, S., Gölge, M., Hill, E. W., Jeziorowska, A., Kalaydjieva, L., Kayser, M., Kivisild, T., Kravchenko, S. A., Krumina, A., 
Kučinskas, V., Lavinha, J., Livshits, L. A., Malaspina, P., Maria, S., McElreavey, K., Meitinger, T. A., Mikelsaar, A., Mitchell, R. J., Nafa, K., Nicholson, J., Nørby, S., Pandya, A., Parik, J., Patsalis, P. C., Pereira, L., Peterlin, B., Pielberg, G., Prata, M. J., Previdere, C., Roewer, L., Rootsi, S., Rubinsztein, D. C., Saillard, J., Santos, F. R., Stefanescu, G., Sykes, B. C., Tolun, A., Villems, R., Tyler-Smith, C. \& Jobling, M. A. (2000) Y-chromosomal diversity in Europe is clinal and influenced primarily by geography, rather than by language. Am J Hum Genet 67. 1526-1543.

Santos, C., Lima, M., Montiel, R., Angles, N., Pires, L., Abade, A. \& Aluja, M. P. (2003) Genetic structure and origin of peopling in the Azores islands (Portugal): the view from mtDNA. Ann Hum Genet 67, 433-456.

Seielstad, M T., Hebert, J. M., Lin, A. A., Underhill, P. A., Ibrahim, M., Vollrath, D. \& Cavalli-Sforza, L. L. (1994) Construction of human Y-chromosomal haplotypes using a new polymorphic A to G transition. Hum Mol Genet 3, 2159-2161.

Seielstad, M. T., Minch, E. \& Cavalli-Sforza, L. L. (1998) Genetic evidence for a higher female migration rate in humans. Nat Genet 20, 278-280.

Semino, O., Passarino, G., Oefner, P J., Lin, A. A., Arbuzova, S., Beckman, L. E., De Benedictis, G., Francalacci, P., Kouvatsi, A., Limborska, S., Marcikiæ, M., Mika, A., Mika, B., Primorac, D., Santachiara-Benerecetti, A. S., Cavalli-Sforza, L. L. \& Underhill, P. A. (2000) The genetic legacy of Paleolithic Homo sapiens sapiens in extant Europeans: a Y chromosome perspective. Science 290, 11551159.

Silva, C., Castro-Oliveira, P., Montiel, R. \& Lima, M. (in press) Population genetics of 5 STRs in San Miguel Island. Antropologia Portuguesa.

Underhill, P. A., Jin, L., Lin, A. A., Mehdi, S. Q., Jenkins, T., Vollrath, D., Davis, R. W., Cavalli-Sforza, L. L. \& Oefner, P. J. (1997) Detection of numerous Y chromosome biallelic polymorphisms by denaturing high-performance liquid chromatography. Genome Res 7, 996-1005.
Underhill, P. A., Shen, P., Lin, A. A., Jin, L., Passarino, G., Yang, W. H., Kauffman, E., Bonne-Tamir, B., Bertranpetit, J., Francalacci, P., Ibrahim, M., Jenkins, T., Kidd, J. R., Mehdi, S. Q., Seielstad, M. T., Wells, R. S., Piazza, A., Davis, R. W., Feldman, M. W., Cavalli-Sforza, L. L. \& Oefner, P. J. (2000) Y chromosome sequence variation and the history of human populations. Nat Genet 26, 358361.

Underhill, P., Passarino, G., Lin, A. A., Shen, P., Mirazón Lahr, M., Foley, R. A., Oefner, P. J. \& Cavalli-Sforza, L. L. (2001) The phylogeography of Y chromosome binary haplotypes and the origin of modern human populations. Ann Hum Genet 65, 43-62.

Veitia, R., Ion, A., Barbaux, S., Jobling, M. A., Souleyreau, N., Ennis, K., Ostrer, H., Tosi, M., Meo, T., Chibani, J., Fellous, M. \& Mc-Elreavey, K. (1997) Mutations and sequence variants in the testis-determining region of the $\mathrm{Y}$ chromosome in individuals with a 46,XY female phenotype. Hum Genet 99, 648-652.

Y Chromosome Consortium (2002) A nomenclature system for the tree of human Y-chromosomal binary haplogroups. Genome Res 12, 339-348.

Zei, G., Lisa, A., Fiorani, O., Magri, C., Quintana-Murci, L. L., Semino, O. \& Santachiara-Benerecetti, A. S. (2003) From surnames to the history of Y chromosomes: the Sardinian population as a paradigm. Eur J Hum Genet 11, 802-807.

Zerjal, T., Dashnyam, B., Pandya, A., Kayser, M., Roewer, L., Santos, F. R., Schiefenhövel, W., Fretwell, N., Jobling, M. A., Harihara, S., Shimizu, K., Semjidmaa, D., Sajantila, A., Salo, P., Crawford, M. H., Ginter, E. K., Evgrafov, O. V. \& Tyler-Smith, C. (1997) Genetic relationships of Asians and northern Europeans, revealed by Y-chromosomal DNA analysis. Am J Hum Genet 60, 1174-1183.

Received: 27 April 2004

Accepted: 30 September 2004 